\title{
Logística aplicada à prestação de serviços: um contexto histórico e conceitual
}

Logística está inserida em todo o processo das 'empresas de serviços' e de seus departamentos, entretanto passa despercebida pelas pessoas, que se utilizam diariamente, para desenvolver suas atividades e alcançar seus objetivos. As maiores dificuldades para empresa prestadora de serviços, consistem na impossibilidade de prever quando, onde, e em que quantidade os equipamentos irão se danificar. Com isto, a logística integrada torna-se o principal diferencial, para as empresas de serviços, pois vem se fortalecendo sua capacidade de atender a diversos tipos de produtos e serviços, com mais velocidade, em cada uma de suas etapas da cadeia de suprimentos, trazendo alta performance e menor custo para o setor de transporte nos processos de coleta e entrega. Diante disso, o objetivo deste trabalho é demonstrar a relevância da logística na prestação de serviços, buscando demonstrar os aspectos econômicos, que possam impactar nos resultados e nos processos de agregação de valores para empresas e clientes. Para isto, se fez necessário conceituar serviços e definir sua qualidade como forma de satisfazer as necessidades dos clientes; Detalhar os principais processos de logística, desde sua história até a atualidade, dando ênfase ao canal de distribuição, que trata da estocagem, movimentação e processamento dos pedidos até o consumidor final; Mostrar a importância do processo de embalagem, principalmente no transporte e na estocagem, com intuito de identificar de que maneira uma empresa de prestação de serviços agrega valores, financeiro e de imagem da marca, perante seus clientes. A metodologia utilizada foi uma pesquisa exploratória e descritiva com um viés qualitativo. Através das análises dos dados, verificou-se que, através de um processo de embalagem adequado, estoques equilibrados, canal de distribuição eficiente e eficaz, e ainda, pessoal capacitado na área de logística, se torna capaz a agregação de valores na execução de suas atividades, tais como: redução de custos dos serviços prestados, qualidade no atendimento aos seus clientes, além da garantia de sua permanência no mercado.

Palavras-chave: Logística; Prestação de Serviço; Serviço.

\section{Logistics applied to the provision of services: a historical and conceptual context}

\begin{abstract}
Logistics is inserted in the whole process of 'service companies' and their departments, however it goes unnoticed by people, who are used daily, to develop their activities and achieve their goals. The biggest difficulties for a service provider are the inability to predict when, where, and how much the equipment will be damaged. With this, integrated logistics becomes the main differential for service companies, as their ability to serve different types of products and services has been strengthened, with more speed, in each of their stages of the supply chain, bringing high performance and lower cost to the transport sector in the collection and delivery process. Therefore, the objective of this work is to demonstrate the relevance of logistics in the provision of services, seeking to demonstrate the economic aspects, which may impact the results and the processes of aggregating values for companies and customers. For this, it was necessary to conceptualize services and define their quality as a way to satisfy customers' needs; Detail the main logistics processes, from their history to the present, emphasizing the distribution channel, which deals with stocking, handling and processing orders to the final consumer; Show the importance of the packaging process, especially in transport and storage, in order to identify how a service provider adds value, financial and brand image, to its customers. The methodology used was an exploratory and descriptive research with a qualitative bias. Through data analysis, it was found that, through an adequate packaging process, balanced stocks, an efficient and effective distribution channel, as well as trained personnel in the logistics area, it is capable of aggregating values in the execution of its activities. activities, such as: cost reduction of services provided, quality service to its customers, in addition to ensuring their permanence in the market.
\end{abstract}

Keywords: Logistics; Service Provision; Service.

Topic: Marketing e Estratégias Mercadológicas

Reviewed anonymously in the process of blind peer.

Renato Lima dos Santos (iD)

Faculdades Integradas Aparício Carvalho, Brasil http://lattes.cnpq.br/2299608233875547

http://orcid.org/0000-0001-8306-3821

renato.fbr@gmail.com

Marcus Vinícius Oliveira Braga (iD

Centro Universitário São Lucas, Brasil

http://lattes.cnpq.br/1683213635601946

http://orcid.org/0000-0001-9965-8125

marcus.braga@saolucas.edu.br

Fabio Herrera Fernandes (iD)

Centro Universitário São Lucas, Brasil

http://lattes.cnpq.br/8154366932618987

http://orcid.org/0000-0003-3242-8303

fabio26012002@gmail.com

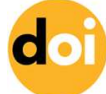

DOI: 10.6008/CBPC2595-4318.2021.001.0002
Received: 20/02/2021

Approved: 22/05/2021

\author{
Junior Cleber Alves Paiva (iD) \\ Faculdade de Ciências e de Tecnologia de Rondônia, Brasil \\ http://lattes.cnpq.br/1965873434054636 \\ http://orcid.org/0000-0002-6938-4351 \\ juniorcleber.ro@gmail.com \\ Rafael Luis da Silva (iD \\ Centro Universitário São Lucas, Brasil \\ http://lattes.cnpq.br/3368127484992279 \\ http://orcid.org/0000-0002-9485-479X \\ rafaeluismat@gmail.com
}

\section{Referencing this:}

SANTOS, R. L.; BRAGA, M. V. O.; FERNANDES, F. H.; PAIVA, J. C. A.; SILVA, R. L.. Logística aplicada à prestação de serviços: um contexto histórico e conceitual. Entrepreneurship, v.5, n.1, p.9-19, 2021. DOI: http://doi.org/10.6008/CBPC2595-4318.2021.001.0002 


\section{INTRODUÇÃO}

A origem da palavra, logística, é essencialmente militar, por isso sua evolução vem desde as grandes guerras para expansão do território macedônio, comandado por Alexandre 'O GRANDE' durante o século IV a.C., que incluiu nos seus exércitos equipes especializadas, que partiam antes das tropas, para montar os armazéns, que supriam de todo mantimento e material bélico necessário para seus exércitos, antes de sua chegada às cidades que seriam invadidas.

De Alexandre 'O GRANDE' até a 2a Guerra mundial, onde a logística teve seu grande impulso, tanto na distribuição e armazenamento, quanto em sua estratégia de localização, a logística era tratada somente no âmbito militar. Só a partir de 1901, depois de perceber seus resultados, a logística passou a ser tratada no meio acadêmico através de publicações de artigos em revistas Paoleschi et al. (2017). Mesmo com a crescente divulgação, só na década de 50 é que as empresas começaram a dar ênfase à satisfação do cliente e logo em seguida os serviços ao cliente passam a ser a peça fundamental da administração de logística.

As necessidades de um país e os excessos de outros, levaram ao rompimento das barreiras comerciais, de modo que não há mais fronteiras para as negociações de produtos e serviços, entretanto é essencial que os gestores do ramo de transportes tenham alguns aspectos que possibilitem uma boa rastreabilidade, rapidez, disponibilidade de seus produtos, sendo acima de tudo, confiável e que tenha capacidade de atender seus diversos clientes com regularidade Bowersox et al. (2008). Neste cenário à 'indústria de serviço' tem crescido em todo mundo, passando a ser a principal geradora de emprego, tendo como base de apoio, a logística aplicada ao setor de serviços que tem se destacado, pois envolve todos os processos de abastecimento e distribuição.

As maiores dificuldades para empresa prestadora de serviços consistem na impossibilidade de prever quando, onde, e em que quantidade os equipamentos irão se danificar. Com isto, a logística integrada tornase o principal diferencial, para as empresas de serviço, pois vem se fortalecendo sua capacidade de atender a diversos tipos de produtos e serviços, com mais velocidade em cada uma de suas etapas da cadeia de suprimentos, trazendo alta performance e menor custo para o setor de transporte nos processos de coleta e entrega (STARKS, 2006).

Apesar dos avanços dos transportes a imprevisibilidade dos serviços e o fato dá logística só ser percebida quando ocorrem erros, provoca uma ansiedade e instiga o desejo de estudar os conceitos de logística de forma detalhada para que se possa demonstrar como uma empresa pode agregar valor para a área de prestação de serviços através da logística.

Diante disso, o objetivo deste trabalho é demonstrar a relevância da logística na prestação de serviços, buscando demonstrar os aspectos econômicos, que possam impactar nos resultados e nos processos de agregação de valores para empresas e clientes.

De certo, a logística está inserida em todo o processo das "empresas de serviços" e de seus departamentos, entretanto passa despercebida pelas pessoas que, de alguma forma, utiliza-se de uma ou várias de suas etapas, diariamente, para desenvolver suas atividades e alcançar seus objetivos, todavia sua 
importância só é percebida quando acontece alguma falha.

\section{METODOLOGIA}

Trata-se uma pesquisa bibliográfica, pois tem como única fonte de informação e dados coletados em artigos científicos, páginas da internet, revistas, livros e documento que podem contribuir em responder ao problema e gerar novos entendimentos em torno dos assuntos abordados (OLIVEIRA et al., 2014). Esta pesquisa classifica-se como explicativa, pois buscou-se relacionar os conceitos e aplicações da logística na área de serviços de manutenção ao resultado proporcionado pelos serviços logísticos de embalagens e distribuição, seja do ponto de visto do cliente ou do fornecedor do serviço. Também é uma pesquisa descritiva, já que mostra as caminhas para agregação de valores financeiro e de fortalecimento da marca através das análises qualitativas que foram realizadas em todo processo do estudo (COOPER et al., 2011). Para chegar aos resultados foram realizadas análises qualitativas dos dados coletados nas diversas leitura e após as interpretações e confronto com as teorias citadas possibilitou responder ao problema da pesquisa proposto (LIRA, 2019).

\section{DISCUSSÃO TEÓRICA}

\section{Empresa de Serviços}

As empresas de serviços, por um período longo, ficaram sendo consideradas, apenas como um suporte à venda de produtos e não havia uma interação entre serviço e manufatura, entretanto existem vários produtos que quando comercializados não podem ser usados pelo consumidor, sem intervenção de profissionais intermediários de serviços. Mas este fato não impede que serviços sejam vendidos isoladamente.

Ainda nesse raciocínio, Cobra et al. (1986) e Kotler (1998), descrevem que o serviço é inodoro, não é palpável e só pode ser experimentado depois de adquirido, mas pode ser vendido separadamente do produto, em algumas vezes a implementação de um serviço está atrelada ao produto, e que sua qualidade pode ser atestada através da satisfação do cliente por terem suas necessidades plenamente atendidas.

Descrever "serviços" não é uma tarefa muito fácil, logo não tem um formato visível e palpável. Já o produto físico, pode ser claramente descrito em termos de seus atributos, como: tamanho, partes, materiais e assim por diante. Estas dificuldades em conceituar "serviços" são reforçadas por Normann (1993) que diz: "Um serviço não pode ser facilmente especificado nem realmente demonstrado antes da compra". Mesmo com todas as dificuldades em definir o que é serviços, o setor vem ganhando forças e atualmente recebeu a denominação de indústria de serviços.

As chamadas 'indústrias de serviços' incluem transporte, comunicações, serviços financeiros, comércio, utilidade pública, serviços profissionais, entretenimento de atendimento à saúde, e dentre outras infinidades. Suas atividades incluem: armazenamento, comercialização, pesquisa de mercado, de distribuição, de reparos e atividades tecnológicas, que podem ser realizadas dentro de uma empresa, seja de 
manufatura ou serviço.

O forte crescimento das empresas de serviços, está, além de outros fatores, ligado ao grande número de itens que precisam ser adquiridos por consequência da compra ou utilização de um 'serviço'. Este conjunto de itens relacionados, oferecidos aos clientes, Normann (1993) descreve como sendo "pacote de serviços". Estes pacotes podem ser formados por novos serviços ou por itens que facilitem sua utilização. Em todos esses "pacotes de serviços" o capital humano é essencial.

O capital humano é o principal recurso das empresas de serviços, que, para realizarem suas atividades sem elevar seus custos, necessitam de processos bem definidos e condizentes com os serviços que estão sendo prestados aos consumidores. Para Slack et al. (1999) "os serviços baseiam-se nas pessoas, enquanto a prestação de serviço em processos". Desta forma, quanto melhor for à qualificação dos profissionais, melhor será percebido o resultado dos serviços prestados. Para uma melhor compreensão do que são estes serviços é preciso conhecer suas características.

\section{Caracterizando 'Serviços'}

O foco do serviço é a satisfação de uma necessidade do cliente, considerando que não é possível ver os serviços, é essencial demonstrar suas características e, por vezes fazer uma comparação com o produto físico, objetivando que o cliente visualize seus benefícios. Uma das diferenças entre produto físico e serviço está na flexibilidade, enquanto que o produto, utilizado de forma diferente do prevista, se torna inaceitável pelo cliente, já no caso dos serviços, podem ocorrer alterações em qualquer etapa do processo, sejam melhorias ou inclusão de novos serviços. Para Cordeiro (2001) “(...) não somente é possível acrescentar novos serviços, como também é difícil não os acrescentar".

Os serviços são produzidos e consumidos simultaneamente, desta forma, não podem ser possuídos e nem tão pouco, armazenados. Outra característica é a facilidade de ser copiado por outras empresas, neste caso o diferencial é o fortalecimento da marca. A padronização e a uniformidade são atributos de difícil estabelecimento e manutenção na prestação de serviços, pois uma empresa pode executar um mesmo serviço de uma forma completamente diferente de outra companhia. O diferencial, entretanto, reside na competência dos profissionais envolvidos.

Para Cobra et al. (1986), "serviços são intangíveis e produto é objeto; serviço é o resultado de desempenho. Quando o serviço é vendido, não há nada mostrado que seja tangível. Os serviços são consumidos mais não podem ser possuídos". Além disso, serviços tem característica bastante divergentes o que faz com que suas características tenham uma forte relação entre cliente e fornecedor, pois a percepção da qualidade de um serviço varia conforme local e tempo de sua aplicação e utilização, sendo que quanto mais se percebe o serviço, como um benefício do produto, mais ele é intangível, e quanto mais se percebe o benefício do produto mais ele se difere de serviço, Berry et al. (1992).

Os produtos e serviços têm em comum a necessidade de serem produzidos com qualidade e de atenderem às exigências dos consumidores por melhorias contínuas. Para que isto ocorra é preciso que se tenha clareza do que significa qualidade de serviços. 


\section{Qualidade do Serviço}

Para Moller (1999) até os anos 80, a qualidade de serviços era considerada como um subproduto e sua aplicação eram apenas para auxiliar nas vendas de produtos físicos, nesta visão os 'serviços' eram entendidos como algo extra relacionado à garantia, reparos e manutenção. Ainda de acordo com Moller (1999), a partir dos anos 80 a qualidade do serviço, na compra e durante o uso de produtos, tem sido um fator que faz a diferença na escolha do fornecedor.

Com os avanços tecnológicos, melhorias na qualidade de educação e uma acessibilidade às informações, têm aumentado o senso crítico do consumidor, que cada vez mais tem buscado seus direitos e exigido mais qualidade no momento da escolha de um produto ou serviço. Moller (1999) enuncia que uma "empresa de serviço" deve ter mecanismo que garantem que as exigências do mercado sejam satisfeitas conforme os padrões de qualidade exigidas por este mercado. É importante ter em mente que uma não reclamação não é sinônimo de satisfação do cliente, quando na realidade o cliente que não reclama, representa uma oportunidade de aprendizagem perdida, além de ser uma ameaça a qualquer empresa de serviço.

Somente através da compreensão das dimensões da qualidade é que a organização será capaz de encontrar medidas para avaliar seu desempenho. Sobretudo, as empresas de prestação de serviços, para atender as necessidades de seus clientes, precisam de comodidades logísticas que atuem com qualidade e agilidade, de forma a ter o material sobressalente e pessoal qualificado, no momento de sua necessidade. Nesse sentido, a escolha dos canais de distribuição pode fazer toda diferença, tanto na qualidade, quanto em seus custos.

\section{Evolução Histórica da Logística}

Nunca se falou tanto sobre logística quanto hoje, principalmente no Brasil, com o crescimento das exportações. Entretanto para se compreender o que realmente significa logística é preciso descrever toda sua trajetória, desde a origem do termo 'logística', até a atualidade, mostrando sua importância para as áreas de serviços de manutenção. Arbache et al. (2004) narra que "A palavra logística é um termo originário do francês (loger, alojar). Muito utilizada pelos militares, para designar a arte de transportar abastecer e alojar as tropas".

No Brasil, a logística ainda é pouco divulgada e mais conhecida como o ato de transportar mercadorias. Um dos motivos de ser pouco conhecida é o fato de não haver disciplinas de logística, na maioria das universidades brasileiras. Outro motivo foi o atraso no desenvolvimento de estudos voltados à sua utilização. No mundo, trata-se de logística desde os anos 50, no Brasil só começou a ser objeto de estudo a partir dos anos 80, quando surgiram os primeiros grupos de estudos em logística. Neste mesmo período, algumas empresas brasileiras começaram a implantar sistemas modernos de logística integrada trazidos do Japão, como o Just in Time (JIT) e o KANBAN, desenvolvidos pela Toyota (GRANT, 2013).

Com a implantação de sistemas integrados, mais modernos como o JIT e outros, surge à necessidade 
de medir sua eficácia, o que fez com que em 1984 fosse criado o primeiro Grupo de Benchmarking em Logística.

Com o crescimento e desenvolvimento da logística precisou-se criar uma associação, o que ocorreu em 1988, com o nome de Associação Brasileira de Logística (ASLOG). Neste mesmo ano cria-se o Pálete Padrão Brasileiro (PBR) e foi criado o primeiro operador logístico.

A partir de 1990, com a abertura do mercado brasileiro as empresas iniciaram um processo de modernização, para se tornarem competitivas no mercado. Com a modernização das empresas prestadoras de serviços foi necessário lançar mão de conceitos de logística para implantação de um sistema que pudesse atender os clientes com qualidade e rapidez.

\section{Conceituando logística}

Para conceituar logística, é preciso que se tenha uma compreensão abrangente do termo logística e para isto é necessário entender, que no mundo contemporâneo, nenhuma área consegue ser produtiva tendo, internamente, setores que não se relacionem entre si. Para tanto, a logística moderna opera com sistemas integrados para que as empresas possam atingir seus objetivos e ser competitivas no mercado.

As empresas de serviços se encaixam bem no conceito de logística, que utilizam em toda sua cadeia produtiva. A definição de logística para Neto (2004) confirma o enunciado quando diz "A logística é a arte e a ciência de determinação de especificações; realização de aquisições; de efetivação da distribuição e finalmente da manutenção em condições de operacionalidade para a vida útil do bem". Sobre este foco a Organização do Tratado do Atlântico Norte (OTAN) também define logística como uma ciência quando diz: "logística é a ciência de planejamento e de realização da movimentação e manutenção das forças".

Toda empresa utiliza-se de logística, sejam ela de serviços ou manufatura, seja para abastecer seus escritórios com material de expediente ou para suprir insumos para produção. Para Heskett (1986), a logística é o gerenciamento de todas atividades que agilizam a movimentação e coordenação dos fornecimentos e pedidos considerando as restrições temporais e espaciais.

Alguns autores, como Gouveia, 1995 que foca o conceito de logística para os canais de distribuição, mostra que o objetivo da logística é garantir que produtos cheguem aos seus destinos no momento desejado, preço justo e da forma adequado. Já Cavanha Filho (2001) apresenta a logística como a mola propulsora da cadeia de suprimentos, atuando deste o início dos fluxos logístico até a concretização das atividades.

"A missão da logística é dispor a mercadoria ou o serviço, no lugar certo, no tempo certo e nas condições desejadas, ao mesmo tempo em que fornece a maior contribuição à empresa" (BALLOU, 2001). Neste processo, é preciso compreender que, por diversos motivos, um produto pode ser devolvido, seja devido ao produto não atender às necessidades do cliente, ocasionado por atrasos na entrega, ou por causa do término de sua vida útil, por estar obsoleto, ser um produto de descarte após consumo, ou prolongamento da vida útil de produtos, foco principal das empresas prestadoras de serviços de manutenção. Todos estes motivos têm sido objetos de estudos dos especialistas em logística, que com tamanhas proporções, ganharam definições próprias e passando a ser chamado de logística reversa. 
Leite (2003), define logística reversa como sendo um processo logístico de retirar produtos novos ou usados de seu ponto inicial na cadeia de suprimento, como devoluções de clientes, inventário excedente ou mercadoria obsoleta, e redistribuí-los usando regras de gerenciamento dos materiais que maximizem o valor dos itens no final de sua vida útil original.

\section{Canal de distribuição}

O processo de distribuição envolve um sistema complexo de atividades, formas de vendas, com intermediários e meios de entregas que constituem, um conjunto integrado necessário para que os serviços das empresas cheguem até o consumidor final. Para Dias (1993), o conceito de distribuição pode ter vários significados e sua definição fica mais clara se for dividida por áreas: Na economia, os produtos são divididos considerando os três fatores de produção, como terra, capital e trabalho, para a gestão de mercado a distribuição se define pelo manuseio dos produtos e serviços, do fornecedor ao cliente, também conhecido como distribuição física ou movimentação física.

Com a introdução dos conceitos de distribuição fica mais simples a procura por melhores preços e prazos de pagamento para as matérias-primas, evitar perdas por falhas na estocagem e manter os custos no menor patamar possível.

Segundo Ballou (1993), “a distribuição física é o ramo da logística empresarial que trata da movimentação, estocagem e processamento de pedidos dos produtos finais da empresa. Para a maioria das empresas, em termos de custos, costuma ser a atividade mais importante, pois absorve cerca de dois terços dos custos logísticos". As Funções de produção e vendas precisam estar interligadas às atividades de distribuição, pois o desempenho destas funções é afetado pelos níveis de atividade de distribuição. Quanto maior for o tempo de planejamento, entre a decisão e a implantação, mais importante se torna o planejamento da distribuição.

Nesse processo, a distribuição pode ser realizada de forma direta ou indireta. A venda direta é aquela que não necessita de nenhum intermediário, a empresa realiza todo o processo de venda diretamente ao consumidor final através de seus órgãos, sejam eles, departamentos, filiais, agências, sucursais, representantes próprios, dentre outros. Na venda indireta, a distribuição do produto ou serviço passa por vários intermediários até chegar ao consumidor final, os intermediários formam os canais de distribuição.

Nas empresas de serviços de manutenção, leva-se em consideração o tipo de equipamento adquirido, o tempo entre a aquisição e a disponibilização da peça de reposição para a logística e o tempo para esta logística entregar ao técnico que vai realizar a manutenção, para isto define-se a meta de ter a peça certa no lugar e tempo certo.

Em grande parte das empresas, os canais de distribuição são essenciais no processo de entrega de bens ou serviços aos clientes. Tais canais são justamente os intermediários, geridos pela própria empresa que adquire os produtos ou serviços e assumem a responsabilidade e o risco de repassá-los ao consumidor final ou a repassar para outro intermediário, que assumirá o risco da compra e da venda. Portanto, os sistemas de distribuição podem ser constituídos de órgãos da própria empresa ou por várias empresas 
intermediárias, que terão a missão de comprar e vender os produtos e serviços.

Para Arbache et al. (2004), o transporte é um elemento de grande peso no custo de distribuição logístico, sendo que, em relação a alguns produtos, influenciam significativamente no alcance dos resultados na prestação dos serviços. Neste prisma, o transporte do retorno de produtos também deve ter seu custo calculado.

Entretanto, como tudo tem um tempo de vida, não seria diferente com produtos e serviços, que tem na logística reversa a possibilidade de prolongar a vida útil, reutilizar produtos ou disponibilizá-lo para reciclagem ou no caso de fim da vida o descarte.

\section{Embalagem}

A embalagem é outro item fundamental para logística, principalmente, durante os processos de estocagem e de distribuição. O melhor pacote otimiza serviço, custo e conveniência. Uma boa embalagem pode ter impacto positivo até na produtividade geral da empresa. Do ponto de vista da logística, a função da embalagem é organizar, proteger e identificar produtos e materiais. Nesse processo, ao agregar peso e espaço, deve-se procurar minimizar estas desvantagens decorrentes destes fatores, utilizando tipos de embalagem alternativos, com o objetivo de minimizar custos e maximizar as vendas.

A boa embalagem garante a estabilidade da carga nos processos de movimentação do material, tanto interno quanto externo. Além disso, deve atender as leis ambientais, bem como contribuir com o marketing através de designe atrativo e que fortaleça a marca. É possível satisfazer os requisitos de armazenagem através da dimensão e empilhamento, com bons padrões de pálete e estocagem eficiente (GURGEL, 2014).

Para se definir uma embalagem de qualidade é necessário conhecer os riscos logísticos, que são definidos de acordo com o ambiente, e as características dos produtos, que são definidas conforme seu tamanho, fragilidade, tipo de material e quanto de peso este produto pode suportar. Para produtos eletrônicos, além do que já foi citado, é preciso conhecer sua sensibilidade aos efeitos das descargas eletrostáticas (ESD), e desenvolver embalagens de acordo com esta sensibilidade (ARAÚJO, 2004). O preço do produto e o meio que serão utilizados para levá-lo até o consumidor final, também deve ser levado em consideração.

Uma boa gestão de logística com foco nos canais de distribuição e nos processos de embalagens não são suficientes para atender as necessidades dos clientes, é preciso manter os níveis de estoque suficientes e, para que isto aconteça, faz-se necessário conhecimento de técnicas de elaboração de planejamento e de controle de estoque.

\section{Planejamento e controle do estoque}

É indispensável um planejamento que permita prever o nível de armazenagem de mercadorias por parte da organização. A oferta e a demanda devem funcionar em sincronia, para a manutenção de estoque seja compatível com as necessidades. Como os produtos nem sempre estão disponíveis, e a demanda é sempre incerta, deve-se manter um estoque para assegurar a disponibilidade das mercadorias, diminuindo 
assim, os custos de produção e distribuição, pois o estoque exerce uma influência muito grande na rentabilidade da empresa.

Ballou (2001), descreve logística como sendo um processo de planejamento, implementação e controle do fluxo, eficiente e economicamente eficaz, de matérias-primas, de estoque em processo, de produtos acabados e de informações relativas, desde o ponto de origem até o ponto de consumo, com o propósito de atender às exigências dos clientes. Para que se possa controlar o nível de estoque, deve-se verificar a demanda que cada produto apresenta. Chiavenato (1991) afirma que "a avaliação dos estoques é o levantamento do valor financeiro dos materiais - desde as matérias-primas iniciais, os materiais em processamento, semiacabados ou acabados, até os produtos acabados - tomando por base o preço de custo ou preço de mercado".

A administração de estoque tem como foco minimizar o investimento em inventario, mantendo, em contrapartida, os níveis de disponibilidade de acordo com as necessidades do mercado. Cabe à logística gerenciar os produtos em todas as etapas do processo, que vai do fornecedor à indústria, desde os pontos de distribuição até o consumidor final, bem como, o retorno destes itens à matriz por excesso de estoque, por obsolescência, ou para serem reparados. Para Dias (1995), enuncia que:

Um sistema de materiais deve estabelecer uma integração desde a previsão de vendas, passando pelo planejamento de programa-mestre de produção e a entrega do produto final. Deve estar envolvido na alocação e no controle da maior parte dos principais recursos de uma empresa: fabricação, equipamento, mão-de-obra e materiais.

A velocidade com que a logística disponibiliza um item de reposição é um dos principais diferenciais para a manutenção dos contratos por parte dos clientes, que quando adquirem um equipamento esperam que este nunca apresente defeito, no entanto caso aconteça uma falha, o cliente espera que seu equipamento seja verificado prontamente. Se por esta falha um item precisar ser substituído, o cliente espera que a substituição aconteça na primeira visita. Caso contrário, o cliente tende a encerrar o contrato ou aplicar multas que, dependendo do tempo de inoperância, podem ter um custo maior que o valor do bem novo.

Muito provavelmente, no término da vida útil do equipamento o cliente mude de marca e dependendo da influência dos clientes no mercado em que atuam, podem influenciar outros a não adquirirem equipamentos deste fornecedor, devido à demora na reposição de itens defeituosos. Para que o cliente tenha seu problema solucionado na primeira visita, é necessário que haja um bom planejamento e um controle efetivo dos estoques, adicionando-se ainda a qualificação técnica.

Ter um controle efetivo dos estoques, não significa racionalizar as compras, a ponto de faltar materiais essenciais para operação, ou adquirir produtos de baixa qualidade para reduzir custos. Para Trigueiro (2007), pelo setor de compras flui grande parte do capital de giro de uma empresa sendo, portanto, compreensível a existência de uma tendência para racionalizar sempre mais esta importante atividade de apoio (melhores compras podem resultar em maiores lucros para a empresa).

Com relação às embalagens, os autores Gurgel (2014) e Araújo (2004) relatam a importância da personalizadas, de acordo com o tamanho, o peso de cada peça e o meio de transporte utilizado. Entretanto, 
não está sendo observado pelas transportadoras o limite máximo de empilhamento e de peso que cada caixa pode suportar, apesar destas informações estarem escritas em todas as caixas. Tal fato deve ser observado em toda a cadeia, já que estes erros podem ocasionar a perda de cliente e de confiabilidade nos serviços prestado (MARTINS et al., 2011). A falta de treinamento das pessoas que trabalham nas transportadoras e na própria empresa leva-os a armazenar e transportar os materiais de forma inadequada, o que pode desagregar todo valor adquirido pelo sistema de embalagem.

Em relação aos níveis de estoque, verificou-se que, os níveis de sobressalentes devem ser suficiente par atender a demando e expectativas dos clientes. Contudo, as empresas precisam ficar em alertas para evitar elevar os custos com o aumento de estoque para compensar atrasos no processo logístico. Neste sentido Ballou (1993) evidencia que as organizações precisam manter controle deste das produções do item até sua utilização no consumidor final, algo imprescindíveis para a logística melhorar seu desempenho e contribuir para os resultados das empresas de serviços de manutenção. Além disso, as empresas de serviços de transporte devem adequar seus contratos para que segam a mesma linha dos contratos que as empresas tenham com seus clientes, assumindo, inclusive parcelas de multas casos estas existam nas cláusulas contratuais (RIBEIRO et al., 2011).

\section{CONCLUSÕES}

Por fim os colaboradores da área serviços de manutenção, precisam ser conscientizados da importância dos serviços logísticos e compreenderem seu fluxo. Pois a imprevisibilidade de defeito pode causar um desbalanceamento nos estoques, e por receio de aumento de custo na estocagem, optam por estoque mínimo o que pode gerar descontentamento de clientes. Falhas neste processo geram indisponibilidade do item, o que pode fazer com que a área de compras adquira novos itens sobressalentes, aumentando, desta forma, os custos com armazenamento e peças obsoletas.

Desta forma, demonstra-se ainda, que através de um processo de embalagem adequada, estoques equilibrados, canal de distribuição eficiente e eficaz, pessoal capacitado na área de logística, a empresa prestadora de serviços acumula, destarte, a agregação valores na execução de suas atividades, tais como: redução de custos dos serviços prestados, qualidade no atendimento aos seus clientes, além da garantia de sua permanência no mercado.

\section{REFERÊNCIAS}

ARBACHE, F.; SANTOS, A.; MONTENEGRO, C.; SALLES, W.. Gestão de logística, distribuição e trade marketing. Rio de Janeiro: FGV, 2004

ARAÚJO, R. L.. As descargas eletrostáticas e a manutenção de equipamentos sensíveis no âmbito do setor elétrico. In: SEMINÁRIO NACIONAL DE DISTRIBUIÇÃO DE ENERGIA ELÉTRICA, 16. Anais. 2004.

BALLOU, R. H.. Logística empresarial: transportes, administração de matérias e distribuição física. São Paulo: Atlas 1993.
BALLOU, R. H.. Gerenciamento da cadeia de suprimentos: planejamento, organização e logística empresarial. 4 ed. Porto Alegre: Bookman, 2001.

BERRY, L. L.; PARASURAMANN A.. Serviços de marketing: competindo através da qualidade. São Paulo: MalteseNonna, 1992.

BOWERSOX, D. J.; CLOSS, D. J.; COOPER, M. B.. Gestão da cadeia de suprimentos e logística. Rio de Janeiro: Campus, 2008.

CAVANHA, F.; ARMANDO, O.. Logística: Novos modelos. Rio 
de Janeiro: QualityMark, 2001.

COOPER, D. R.; SCHINDLER, P. S.. Método de pesquisa em administração. 10 ed. Bookman, 2011.

CORDEIRO, N. R.. Construção de um Modelo de Gestão Estratégica para Organizações Prestadoras de Serviços Utilizando o Balanced Scorecard, o Gerenciamento de Processos e o Marketing de Relacionamento. Dissertação (Mestrado em Engenharia da Produção) - Universidade Federal de Santa Catarina, Florianópolis, 2001

CHIAVENATO, I.. Iniciação à administração de manterias. São Paulo: Makron Mcgraw - Hill, 1991.

COBRA, M.; ZWARG, F.. Marketing de serviços: conceitos e estratégias. São Paulo: McGraw-Hill, 1986.

DIAS, M. A. P.. Administração de matérias: uma abordagem logística. 4 ed. São Paulo: Atlas, 1993.

DIAS, M. A. P.. Administração de materiais compacta. 4 ed. São Paulo: Atlas, 1995

GRANT, D. B.. Gestão de logística e cadeia de suprimentos. São Paulo: Saraiva, 2013.

GURGEL, F. A.. Administração da embalagem. 2 ed. Rio de Janeiro: Cengage Learning Brasil, 2014.

HESKETT, J. L.. Managing in the service economy. Harvard Business School Press, 1986.

KOTLER, P.. Administração de marketing: análise, planejamento, implementação e controle. São Paulo: Atlas, 1998.

LEITE, P. R.. Logística reversa: meio ambiente e competitividade. São Paulo: Prentice Hall, 2003.
LIRA, B. C.. Passo a passo do trabalho científico. São Paulo: Vozes, 2019.

MARTINS, R. S.; XAVIER, W. S.; SOUZA FILHO, O. V.; MARTINS, G. S.. Gestão do transporte orientada para os clientes: nível de serviço desejado e percebido. Revista de Administração Contemporânea, v.15, n.6, p.1100-1119, 2011. DOI: http://doi.org/10.1590/S141565552011000600008

MOLLER, C.. O Lado Humano da Qualidade: Maximizando a qualidade de produtos e serviços através do desenvolvimento das pessoas. 12 ed. São Paulo: Pioneira, 1999.

NETO, J. M. U.. Uma análise do funcionamento da logística da Itautec. Com Serviços S/A. João Pessoa, 2004.

NORMANN, R.. Administração de serviços: estratégia e liderança na empresa de serviço. São Paulo: Atlas, 1993.

OLIVEIRA, E. R.; FERREIRA, P.. Métodos de investigação: da interrogação à descoberta científica. Vida Econômica, 2014.

PAOLESCHI, B.; CASTIGLIONI, J. A. M.. Introdução à Logística. São Paulo: Saraiva, 2017.

RIBEIRO, R. B.; HENRIQUE, E. C. S.; CORDEIRO, L. A.. Análise da logística terceirizada do transporte rodoviário de cargas: um estudo teórico. Revista de Administração do UNIFATEA v.4, n.4, 2011.

SLACK, N.; CHAMBERS, S.; HARLAND, C.; HARISSON, A.. Administração da produção. São Paulo: Atlas, 1999.

STARKS, G.. The evolution and adoption of a supply chain focus in public organizations. Contract Management, 2006.

TRIGUEIRO, F. G. R.. Logística reversa: a gestão do ciclo de vida do produto. Logística, 2007.

A CBPC - Companhia Brasileira de Produção Científica (CNPJ: 11.221.422/0001-03) detém os direitos materiais desta publicação. Os direitos referem-se à publicação do trabalho em qualquer parte do mundo, incluindo os direitos às renovaç̃oses, expansões e disseminações da contribuiç̃o, bem como outros direitos subsidiários. Todos os trabalhos publicados eletronicamente poderão posteriormente ser publicados em coletâneas impressas sob coordenação da Sustenere Publishing, da Companhia Brasileira de Produção Científica e seus parceiros autorizados. Os (as) autores (as) preservam os direitos autorais, mas não têm permissão para a publicação da contribuição em outro meio, impresso ou digital, em português ou em tradução. 